\title{
Medicinal Product Classification
}

National Cancer Institute

\section{Source}

National Cancer Institute. Medicinal Product Classification. NCI Thesaurus. Code C156643.

The categorization of medicinal products based on chemical, pharmacological, or therapeutic properties or regulatory status. 